\title{
The relationship between the spasticity-related pain and the quality of life about the cerebral palsy in China
}

\begin{abstract}
Purpose: Children and adolescents with cerebral palsy suffered from spastic pain that affected their quality of life. The purpose of this study was to examine the relationship between the spasticity-related pain and the quality of life about the children with cerebral palsy with spasticity-related pain in China.
\end{abstract}

Methods: This was a prospective, observational, one-arm multicentre study. 137 cerebral palsy children with SRP and their parents/caregivers were recruited from three sites in China. The children and their parents/caregivers completed the Questionnaire on Pain Caused by Spasticity and PedsQLTM 4 scale.

Results: 137 children with their parents/caregivers were eligible for participation in the study, and all completed the relevant investigation. According to the result of the children-report PedsQL, the total scale scores in the V2/V3 about the different age groups (5-7years old ,8-12 years old, 13-16 years old ) had no statistic significance $((\mathrm{P}>0.05)$. After 3 weeks, the change compared to first time survey result was not significant $(p>0.05)$. The total scores and each domain of PedsQL in the CP with SRP was lower than the normal group $(\mathrm{P}<0.05)$. On the whole, the associations between the child and parent proxy-report QPS total scores and each domain scores of PedsQL were moderate to high. The PedsQL total scores relationship to the QPS item score was moderate.

Conclusion: The quality of life in the CP patients with SRP was worse than normal people and it was a steady long-term stage. The correlation between the spasticityrelated pain and the quality of life was moderate to high and negative and the result from the parent proxy-report was more evident.

Keywords: cerebral palsy children, spasticity-related pain, quality of life
Volume 3 Issue 2 - 2018

\author{
Liu Zhen-huan,' Dong Shang-sheng ${ }^{2}$ \\ 'Nanhai Hospital of Women and Children Affiliated, Guangzhou \\ University of Chinese, China \\ ${ }^{2}$ Graduate School of Guangzhou University of Chinese \\ Medicine, China
}

Correspondence: Liu Zhen-huan, Professor, Chief physician, Doctoral Supervisor received the special state Council allowance in China, Research direction in Neuro-rehabilitation of children. Women and Children Hospital Affiliated to Guangzhou University of Traditional Chinese Medicine, China, Email Izh1958424@I63.com

Received: February 18, 2018 | Published: March 02, 2018

\section{Background}

Cerebral palsy (CP) is defined as a group of permanent disorders of the development of movement and posture, causing activity limitation, attributed to non-progressive disturbances occurring in the developing fetal or infant brain. ${ }^{1}$ Lesions to the sensorimotor cortex, subcortical axon tracts, and sub plate are often implicated, with other motor and non-motor areas frequently also affected. The etiology is complex and often multi-factorial; causes include hypoxia, stroke, infection, trauma, and genetic factors., ${ }^{2,3}$ The difference of the incidence of cerebral palsy in developed countries had no significance. Reported by $14 \mathrm{CP}$ research centers in Europe, the incidence was about 2 3\%. And the WHO reported that the incidence was $2.2 \%$, and the latest reports in China showed that the incidence was about $2.1 \%$. ${ }^{4,5}$

Cerebral palsy (CP) syndromes was character by impaired motor function. Most children with this development disorder also suffered from sensory, communicative, and intellectual impairments and might have complex limitations in self-care functions. Although care-giving was a normal part of being the parent of a young child, this role may take on an entirely different significance when a child experienced functional limitations and possible long-term dependence. ${ }^{6}$ At least $60 \%$ of the adults with spastic bilateral cerebral palsy had difficulties with mobility, recreation and housing, and $44 \%$ had difficulty with personal care and employment. A significant number of adults with spastic bilateral cerebral palsy encountered difficulties in social participation and had a low perceived health-related quality of life in physical functions. ${ }^{7,8}$

In China, several researches about the quality of life in the children with cerebral palsy and their parents, using the PedsQL ${ }^{\mathrm{TM}} 4.0$ and SF-36 scale, showed that the four domains (physiological function, emotional function, social function, school function) and total scores of PedsQL were lower than that of the normal group $(\mathrm{P}<0.05)$, and that the scores of SF-36 about the body pain, general health, vitality, social function, mental function and the total score were lower than that of normal group $(\mathrm{P}<0.01){ }^{9,10}$

Spastic pain was a serious complication of cerebral palsy which made the children with $\mathrm{CP}$ suffered. ${ }^{11}$ The spasticity was due to 
the central motor neurons destruction lead to the muscle which was under the control of lower neurons excessive contraction. Spasm can maintain the children' posture, which was positive, but excessive spasm would limit children' daily activities, lead to joint deformity and hand functional abnormalities. According to a latest report, $50 \%$ of patients with cerebral palsy suffered from pain, making about $25 \%$, who should be able to walk, back to the wheelchair. So the spasticity seriously influenced children' quality of life. ${ }^{12}$ beside the physiological effects, pain in individuals with cerebral palsy was responsible for the reductions of psychological of healthrelated quality of life. ${ }^{13}$

Spastic pain, as the most important symptoms of cerebral palsy, recently becomes popular in the researches about its pathology and treatment. And as we known, botulinum toxin had made a very great progress in the study of spastic pain caused by spasm, and could improve the quality of life of cerebral palsy children. Researchers showed that botulinum toxin injection could improve the posture in the sitting position and facilitates the fitting of orthotic devices. ${ }^{14,15}$ Rivard found that overall parent ratings of their children' pain were significantly reduced after botulinum toxin A injection, parents of $62 \%$ cases reported the absence of pain 1 month after injection (proportion $=0.38 ; 95 \%$ confidence interval $=0.23-0.55){ }^{6,16}$

Our study is prospective, observational, one-arm multicentre. Aims of study:

a. To assess QoL of the cerebral palsy children with spasticity-related pain, reported by both children and their parent or caregivers.

b. To investigate the change of quality of life before and after 3 weeks.

c. To study the relationship between the quality of life and the spasticity-related pain.

\section{Methods}

\section{Procedure and participants}

This was a prospective, observational, one-arm multicentre study 137 cerebral palsy children with spasticity-related pain and their parents/caregivers were recruited from three sites in China (Nanhai Affiliated Maternity and Children Hospital of Guangzhou University of Traditional Chinese Medicine; The Maternity and Child Health care Hospital of Dongguan; Xiang YaBoAi Rehabilitation Hospital). The three sites recruited both from their inpatient caseload and their outpatient caseload .The subjects experienced intermittent SRP and had a clinical diagnosis of spasticity and active treatment or medication of spasticity. Caregiver or parents had regular (at least daily) contact with the subject to be able to report on the observed SRP behaviors. The investigator considered in advance whether the subject and caregivers were able to attend the scheduled visits as planned. The study participant was asked to take part in a Screening process (V1), a Baseline assessment process (V2), and an End of Study follow up assessment (V3). In fact, the Screening and Baseline measures ended up being obtained for all subject during the same day directly after another. Therefore, two and not three separate study visit was performed by all participants: the Screening/Baseline Visit (V1/2) and the End of Study Visit (V3). The End of Study Visit was to be scheduled 3 weeks (21 \pm 3 day) following the Baseline assessment (V2) (Table 1).
Table I The schedule of the study assessments.

\begin{tabular}{|c|c|c|}
\hline Measurement event & $\begin{array}{l}\text { Screening / } \\
\text { Baseline } \\
\text { Visit V1/ V2 } \\
\text { (Day 1) }\end{array}$ & $\begin{array}{l}\text { End of } \\
\text { Study } \\
\text { Visit V3 } \\
\text { (Day 21 } \pm 3 \text { ) }\end{array}$ \\
\hline Informed Consent & $\mathrm{X}$ & \\
\hline Inclusion/Exclusion Criteria & $\mathrm{X}$ & \\
\hline Demographics \& Medical History & $\mathrm{X}$ & \\
\hline Description of Cognitive Abilities & $\mathrm{X}$ & \\
\hline Cerebral Palsy-Related Therapies & $\mathrm{X}$ & $X$ \\
\hline $\begin{array}{l}\text { Questionnaire on Pain caused by Spasticity } \\
\text { (QPS) }\end{array}$ & $\mathrm{X}$ & $\mathrm{X}$ \\
\hline $\begin{array}{l}\text { Key problems \& ease of use of } \\
\text { Questionnaire }\end{array}$ & $\mathrm{X}$ & $X$ \\
\hline $\begin{array}{l}\text { Pediatric Quality of Life Inventory }{ }^{\mathrm{TM}} \\
\left(\text { PedsQL }^{\mathrm{TM}}\right)\end{array}$ & $\mathrm{X}$ & $\mathrm{X}$ \\
\hline $\begin{array}{l}\text { Intelligence and Cognitive function } \\
\text { questionnaires }\end{array}$ & $\mathrm{X}$ & $\mathrm{X}$ \\
\hline
\end{tabular}

\section{Inclusion criteria}

i. Male or female child or adolescent (minimum age 2 years; maximum age 17 years).

ii. Child/Adolescent has either uni- or bilateral CP.

iii. Child/Adolescent has UL and/or LL spasticity.

iv. Child/Adolescent has presence of intermittent SRP in either the ULs and/or LLs.

v. SRP must be experienced by the child/adolescents at least on a weekly basis.

vi. Ashworth Score of $\geq 1$ in one of the following clinical patterns (uni- and/or bilateral) of the child/adolescents in which SRP is experienced: pes equinus, adducted thigh, flexed knee, flexed elbow, or flexed wrist.

vii. Child/adolescent received continuous anti-spastic treatment and/ or medication.

viii. The caregiver has an understanding of the nature of the study and the study procedures and is willing to participate in the study and consent to their child's participation in the study.

\section{Exclusion criteria}

a. Child/Adolescent has fixed contractures (defined as severe restriction of the range of joint movement on passive stretch in the target clinical pattern(s)).

b. Child has predominant forms of muscle hypertonia other than spasticity (e.g., dystonia) in the target limb(s) of the children/ adolescents.

c. Child/Adolescent has constant SRP or chronic pain due to other reasons (e.g. hip edslocation/ subluxation) over very long time periods).

d. Child/Adolescent has had surgery in the LLs and/or ULs within past 12 months.

e. Child/Adolescent has indication for orthopedic surgery within the next 2 months. 
f. Child/Adolescent has pure dyskinetic CP or mixed CP with predominantly dyskinetic (dystonic or choreo-athetotic), ataxic (hypotonic), or mixed $\mathrm{CP}$ with predominantly dyskinetic or ataxic movements.

g. Child has any other comorbid condition that in the opinion of the clinician would confound the study results on the experienced SRP.

h. Child has participated in a therapeutic clinical study within the last 12 week prior to the screening visit 1 (V1) or ongoing participation in a study.

\section{Measure}

\section{Health-related quality of life (HRQoL)}

The HRQoL was assessed by a version of the Pediatric Quality of Life Inventory TM (PedsQL ${ }^{\mathrm{TM}}$ ) that was adapted and validated for the Chinese population by Yeung et al. ${ }^{19}$ This questionnaire could be used to assess HRQoL on healthy children and adolescents, and in those with acute and chronic health conditions, and consists of 23 items comprising four multidimensional scales:

i. Physical functioning (eight items)

ii. Emotional functioning (five items)

iii. Social functioning (five items)

iv. School functioning (five items)

v. Psychosocial Functioning Summary(emotional functioning, social functioning, school functioning). ${ }^{17-19}$

Items are reverse scored and linearly transformed to a $0-100$ scale $(0=100 ; 1=75 ; 2=50 ; 3=25 ; 4=0)$, so that higher scores indicate better HRQoL. For the study, the set of Generic Core Scales 4.0 will be used the fit the respective age groups of the study population:

a) Toddler version (Age 2-4), parent proxy-report

b) Young child version(Age 5-7), child self-report and parent proxyreport

c) Child version (Age 8-12), child self-report and parent proxyreport

d) Adolescent version (Age 13-18), child self-report and parent proxy-report

\section{Questionnaire on pain caused by spasticity (QPS)}

The QPS is the primary study assessment of this study and will be administered at visit 2 (V2) and visit 3 (V3). The questionnaire is a PRO for children and adolescents (2-17 years) with CP and SRP with an ObsRO for their caregiver. The QPS consists of six modules. A self-report version for the children/adolescent (11 items), an interview-version for the children/adolescent (11 items), and a proxyreport version for the parent(s)/caregiver (12 items) are each available for UL and LL SRP assessment. While pain intensity is reported by the child/adolescent, pain frequency based on observed pain behaviors are documented by the parent(s)/caregiver(s). Thus, the information provided by children/adolescents complements with that of the parent(s)/caregiver(s). Pain intensity and frequency of the QPS are assessed for general pain and for four different activity situations. The situations are described in different questions at rest, normal day activities, and physical exercise and for an individual defined very hard thing to do for the children/adolescents. It is first asked for each situation whether pain occurred (Yes/No) and then how pain severity was experienced on the 6-point Wong-Baker FACES ${ }^{\circledR}$ scale by the children or adolescents or how pain frequency was observed by the caregivers by using a 5 -point response scale $(0=\text { never }-4=\text { always })^{20}$ (Table 2)

Table 2 Concepts in spasticity-related pain in the QPS.

\begin{tabular}{llll}
\hline Child/adolescent modules (upper and lower extremity) & & Parent/caregiver modules (upper and lower extremity) \\
\hline Targeted symptom concepts & Item & Targeted symptom concepts \\
\hline Spasticity & 1 & Spasticity (observed) \\
General spasticity-related pain (SRP) & 2 & General SRP (verbalization) \\
General SRP severity & 3 & General SRP (observed signs) \\
SRP while at rest & 4 & General SRP observed frequency \\
SRP while at rest severity & 5 & SRP while at rest (observed signs) \\
SRP during usual activities & 6 & SRP while at rest observed frequency \\
SRP during usual activities severity & 7 & SRP during usual activities (observed signs) \\
SRP during active mobilization & 8 & SRP during usual activities observed frequency \\
SRP during active mobilization severity & 9 & SRP during active mobilization (observed signs) \\
SRP during difficult activity & 11 & SRP during active mobilization observed frequency \\
SRP during difficult activity severity & 12 & SRP during difficult activity (observed signs) & 96 \\
& & SRP during difficult activity observed frequency & 10 \\
\hline
\end{tabular}

\section{Data quality assurance}

The initial step in assuring the quality of the data was to institute a training session of the assessment staff at all three sites. A day was established at the start of the study to have the lead site investigators and 3-4 of the key meet together at one hospital site. The Principal
Investigator at the Naihai site is a expert in the field of working with children and was responsible for assuring that all tests and evaluations were performed according to appropriate standards and methods and methods at their own site and observed the tests being perform at the other two sites in order to achieve comparable quality and consistency. 


\section{Statistical analysis}

Descriptive statistics (mean, standard deviation, and range for quantitative variables; frequency and percentage for categorical variables) were presented for children and their parent's demographic variables and the score of the PedsQL. The scores of quality of life in the cerebral palsy were analyzed using independent sample $t$ tests and the scores change were used the paired sample test. Pearson or Spearman correlations were used to determine the associations between quality of life and the QPS. All statistical tests were twotailed, and $\mathrm{p}<0.05$ was regarded as being statistically significant.

\section{Ethics conduct of the study}

This study was conducted in accordance with the ethics principles that have their origin in the Declaration of Helsinki and are consistent with ICH-GCP requirements and the ethics committee standards for China. All parents gave written informed consent and the permission for their children to participate prior to inclusion in the study.

\section{Results}

\section{Demographics \& descriptive analyses}

Of 137 patients and their parents/caregiver (planed 135cases, actuall 137) eligible for participation in the study, and completed the relevant investigation. By site, enrollment was 21 subjects in Dongguan, 56 subjects in Nanhai, and 60 subjects in Hunan. The mean age of the participants was 6.6 years (SD 3.2 years, range $0-17.5)$. Gender distribution was even to 94 boys $(68.6 \%)$ and $93 \%$ were Chinese. Their level of education was in the elementary school stage. The average age of diagnosis of CP and spasticity type is 1.8 years (SD 1.7 years, range $0.1-10$ ) and 1.9 years (SD 1.6 years, range $0.1-10)$. The premature delivery (51\%) and the lack oxygen was the most important causation of CP. The bilateral LL spasticity $(\mathrm{N}=117$, $85 \%)$ is the most common type; The UL spasticity ( $\mathrm{N}=10,7 \%)$ usually was associated with LL spasticity. About the FMFCS-E\&, Class I(27, $19.7 \%)$, Class II (46,33.6\% ), Class III(29,21.2\%), Class IV(13,9.5\%), Class V(22, 16.1\%); MACS Class I (40, 29.2\%), Class II (49,35.8\%), Class III $(30,21.9 \%)$, Class IV $(10,7.3 \%)$, Class V(4,2.9\%), missing $(4,2.9 \%)$ (Table 3$)$.

The mean age of the parents/caregivers was 39.6 years (SD 11 years, range 24.9-69.1). Gender distribution was 114 female (83.2\%) and $90.5 \%$ were married. The situation of their education was elementary school (23.4\%), high school (54.7\%), and university (21.9\%). Most of them quit the job and take care of their children all dayf in the rehabilitation institution, about 69(50.4) not employed, 29(21.2) employed full time, not employed outside the home (homemaker) 26(19.0), employed part time 8(5.8), retired 5(3.6).

According to the result of the children-report PedsQL, the total scale scores in the V2/V3 about the different age groups (5-7years old ,8-12 years old, 13-16 years old ) had no statistic significance((P $>0.05)$. After 3 weeks, the change about two time survey result was not significant $(\mathrm{p}>0.05)$, and the range of the total scale and domain scores was from 0.4 to 1.3 (Table4).

The result from the parent proxy-report PedsQL was similar to the children-report .Compared to the data by the parent proxy-report PedsQL from the Chinese normal group (mean age 6.04 years, SD 3.09 years, range 2-12 years, 68 male, 32 female), we found that total scores and each domain of quality of life on CP with SRP is lower $(\mathrm{P}<0.05)$ (Table 5).

Table 3 Demographic characteristic CP children

\begin{tabular}{|c|c|}
\hline Item & $\mathbf{N}=\mathbf{1 3 7}$ \\
\hline Age & $6.6(3.2,2.0-17.5)$ \\
\hline \multicolumn{2}{|l|}{ Gender n (\%) } \\
\hline Female & $43(31.4)$ \\
\hline Male & $94(68.6)$ \\
\hline Education(highest grade completed ) & $0.5(1.4,0-10)$ \\
\hline \multicolumn{2}{|l|}{ Education category } \\
\hline Elementary school & $136(99.3)$ \\
\hline High school & $1(0.7)$ \\
\hline \multicolumn{2}{|l|}{ Ethnic group } \\
\hline Chinese & $128(93.4)$ \\
\hline Non-Chinese & $9(6.6)$ \\
\hline Age at $\mathrm{CP}$ diagnosis & $1.8(1.7,0.1-10)$ \\
\hline Age at spasticity diagnosis & $1.9(1.6,0.1-10)$ \\
\hline \multicolumn{2}{|l|}{ Main cause of $C P$} \\
\hline Premature delivery & $70(51.1)$ \\
\hline Lack oxygen & $46(33.6)$ \\
\hline Low birth weight & $13(9.5)$ \\
\hline Brain condition & $9(6.6)$ \\
\hline Reason unclear & $12(8.8)$ \\
\hline Other cause & $25(18.2)$ \\
\hline \multicolumn{2}{|l|}{ FMFCS-E\&R } \\
\hline Class I & $27(19.7)$ \\
\hline Class II & $46(33.6)$ \\
\hline Class III & $29(21.2)$ \\
\hline Class IV & $13(9.5)$ \\
\hline Class V & $22(16.1)$ \\
\hline \multicolumn{2}{|l|}{ MACS } \\
\hline Class I & $40(29.2)$ \\
\hline Class II & $49(35.8)$ \\
\hline Class III & $30(21.9)$ \\
\hline Class IV & $10(7.3)$ \\
\hline Class V & $4(2.9)$ \\
\hline missing & $4(2.9)$ \\
\hline \multicolumn{2}{|l|}{ Limb spasticity identification } \\
\hline Bilateral upper & $7(5.1)$ \\
\hline Unilateral upper-R & $3(2.2)$ \\
\hline Bilateral lower & $84(61.3)$ \\
\hline Unilateral lower-R & $1(0.7)$ \\
\hline Bi lower + bi upper & $29(21.2)$ \\
\hline Lower-R + upper-R & $5(3.6)$ \\
\hline Lower-L + upper-L & $4(2.9)$ \\
\hline Bi lower + uni upper-L & $4(2.9)$ \\
\hline
\end{tabular}


Table 4 The V2/V3 standardized T-scores on health-related quality of life domains in individuals with cerebral palsy (CP) as assessed by the children

\begin{tabular}{|c|c|c|c|c|c|c|}
\hline \multirow{2}{*}{ Item } & \multirow{2}{*}{$\mathbf{N}$} & \multicolumn{2}{|l|}{ V2 } & \multicolumn{2}{|l|}{ V3 } & \multirow{2}{*}{$\begin{array}{l}\text { V2/V3 } \\
\text { Change Mean(SD) }\end{array}$} \\
\hline & & Mean(SD) & Median(Range) & Mean(SD) & Median(Range) & \\
\hline Total Scale Score(5-7) & 71 & $54.4(13.2)$ & $54.3(15.2-80.4)$ & $54.0(13.3)$ & $56.6(15.2-80.4)$ & $-0.2(3.4)$ \\
\hline Total Scale Score(8-12) & 21 & $49.2(11.7)$ & $50(29.3-66.3)$ & $50.4(12.5)$ & $50(29.3-70.7)$ & $1.2(2.8)$ \\
\hline Total Scale Score(13-18) & 7 & $55.6(14.5)$ & $60.9(26.4-66.7)$ & $56.9(15)$ & $60.9(27.8-69.4)$ & $1.3(1.3)$ \\
\hline \multicolumn{7}{|l|}{ CHILD(Combined) } \\
\hline Physical Functioning & 99 & $40.1(20.3$ & $37.5(0-87.5)$ & $41.2(21$ & $39.1(0-87.5)$ & $1.3(5.6)$ \\
\hline Emotion Functioning & 99 & $70.9(15.5)$ & $70(30-100)$ & $70.1(15.4)$ & $70(30-100)$ & $-0.8(5.4)$ \\
\hline Social Functioning & 99 & $58.3(19.2)$ & $60(20-100)$ & $58(19.2)$ & $60(20-100)$ & $-0.4(6)$ \\
\hline School Functioning & 80 & $52.9(20.9)$ & $55(0-100)$ & $52.1(19.9)$ & $50(0-100)$ & $-0.4(6)$ \\
\hline Psychosocial Functioning & 99 & $61.5(13)$ & $63.3(23.3-95)$ & $60.8(12.8)$ & $63.3(23.3-100)$ & $-0.5(3.9)$ \\
\hline Total Scale Score & 99 & $53.4(13)$ & $54.3(15.2-80.4)$ & $53.5(13.2)$ & $55.1(15.2-80.4)$ & $0.2(3.3)$ \\
\hline
\end{tabular}

Note V2 and V3 was conducted paired sample $T$ test, all the result have no significance $(P>0.05)$

The total scores of different age group were conducted one-way ANOVA, the result: $p-v 2=0.25, p-v 3=0.43$

Table 5 The V2/V3 of the CP with SRP and normal group standardized T-scores on health-related quality of life as assessed by the parents/caregivers

\begin{tabular}{|c|c|c|c|c|c|c|}
\hline \multirow{2}{*}{ Item } & \multirow{2}{*}{$\mathbf{N}$} & \multicolumn{2}{|l|}{ V2 } & \multirow{2}{*}{ V2/V3Change Mean(SD) } & \multirow{2}{*}{$\begin{array}{l}\mathbf{N} \\
\text { (Normal) }\end{array}$} & \multirow{2}{*}{ Mean(SD) } \\
\hline & & Mean(SD) & Mean(SD) & & & \\
\hline Physical Functioning & 136 & $34.7(20.6)$ & $35.2(20.9)$ & $0.3(4.5)$ & 100 & $95.89(8.63)^{*}$ \\
\hline Emotion Functioning & 136 & $63.3(13.3)$ & $63.6(12.8)$ & $0.2(5.5)$ & 100 & $96.34(4.16)^{*}$ \\
\hline Social Functioning & 136 & $46.4(16.8)$ & $46.7(17.2)$ & $0.2(5.2)$ & 100 & $88.6(7.88)^{*}$ \\
\hline School Functioning & 90 & $39.9(23.9)$ & $39.7(23.8)$ & $-0.3(5.6)$ & 100 & $87.39(11.22)^{*}$ \\
\hline Psychosocial Functioning & 136 & $51.8(13.4)$ & $52(13.2)$ & $0.1(4.2)$ & 100 & $89.63(7.85)^{*}$ \\
\hline Total Scale Score & 136 & 45.1(13.8) & $45.4(14)$ & $0.2(3.4)$ & 100 & $87.39(11.22)^{*}$ \\
\hline
\end{tabular}

Note The normal group quality of life date was provided by Dr. Zhenhuan Liu.V2 and V3 was conducted paired sample T test all ,all the result have no significance $(P>0.05)$.

$*_{\mathrm{P}}$ value is significant at the 0.05 level (2-tailed)

Table 6 The QPS total scores relation to the each domain of PedsQL TM

\begin{tabular}{|c|c|c|c|c|c|c|}
\hline $\begin{array}{l}\text { PedsQL } \\
\text { Combined }\end{array}$ & $\begin{array}{l}\text { (self) child } \\
\text { lower } \\
\text { extremities }\end{array}$ & $\begin{array}{l}\text { (self) child } \\
\text { upper } \\
\text { extremities }\end{array}$ & $\begin{array}{l}\text { (interviewer) } \\
\text { child lower } \\
\text { extremities }\end{array}$ & $\begin{array}{l}\text { (interviewer) child } \\
\text { upper extremities }\end{array}$ & $\begin{array}{l}\text { parent lower } \\
\text { extremities }\end{array}$ & $\begin{array}{l}\text { parent upper } \\
\text { extremities }\end{array}$ \\
\hline $\begin{array}{l}\text { Physical } \\
\text { Functioning }\end{array}$ & -0.191 & 0.006 & $-0.616^{* *}$ & -0.816 & $-0.462 * * *$ & -0.151 \\
\hline $\begin{array}{l}\text { Emotion } \\
\text { Functioning }\end{array}$ & -0.081 & -0.321 & $-0.464 *$ & $-0.951 * *$ & $-0.144 * * *$ & -0.342 \\
\hline $\begin{array}{l}\text { Social } \\
\text { Functioning }\end{array}$ & $-0.343 * *$ & -0.247 & $-0.56 * *$ & -0.713 & $-0.427 * * *$ & $-0.472 * * *$ \\
\hline $\begin{array}{l}\text { School } \\
\text { Functioning }\end{array}$ & -0.237 & 0.127 & -0.464 & $\mathrm{a}$ & -0.176 & -0.375 \\
\hline $\begin{array}{l}\text { Psychosocial } \\
\text { Functioning }\end{array}$ & $-0.323 * *$ & -0.274 & $-0.641^{* *}$ & -0.876 & $-0.310 * * *$ & $-0.486 * * *$ \\
\hline Total Scale Score & $-0.325^{* *}$ & -0.136 & $-0.685 * *$ & -0.861 & $-0.441 * * *$ & $-0.375 * *$ \\
\hline
\end{tabular}

Note PEARSON CORRELATIONS (Spearman coefficients were also examined with similar results)

* Correlation is significant at the 0.05 level (2-tailed)

** Correlation is significant at the 0.01 level (2-tailed)

*** Correlation is significant at the 0.00 I level (2-tailed)

a, Cannot be computed because at least one of the variables is constant 
On the whole, the associations between the child and parent proxy-report QPS total scores and PedsQL each domain scores were moderate to high. But the relationship of different QPS version and PedsQL scores was very different. The first one, most LL/UL parent proxy-report QPS category reaches the significance at $\mathrm{P}<0.01$, compared to the LL/UL child QPS category. The second is larger group the LL Child/parent QPS category reach the significance at $\mathrm{P}<0.01$, compared to the UL Child/parent QPS category. However, even for the UL QPS modules, high correlation coefficients are evident, although not reaching always significance. All the correlation between school function and six QPS modules is mild and not reach significance (Table 6).

The relationship between PedsQL total scores and the QPS item score was moderat, which presented for the five daily situations (QPS3 for the general SRP severity, the QPS-5 for SRP at rest, the QPS7 for SRP at activity, QPS-9 for SRP at mobilization, QPS -12 for SRP at doing hard activity). It had similar result above. The parent proxy-report PedsQL total scores always reach the significance at five situation $(\mathrm{P}<0.01)$, compared to the child version. The correlation of LL PedsQL total scores and the five situations was more significant than that of UL (Table 7).

Table 7 The QPS item scores relation to the total scores of PedsQL TM

\begin{tabular}{|c|c|c|c|c|c|}
\hline PedsQL total scale scores & QPS-3 & QPS-5 & QPS-7 & QPS-9 & QPS-12 \\
\hline (self) child lower extremities & -0.026 & -0.091 & $-0.266^{*}$ & $-0.25^{*}$ & -0.238 \\
\hline (self) child upper extremities & -0.055 & 0.187 & 0.063 & -0.149 & -0.148 \\
\hline (interviewer) child lower extremities & -0.222 & $-0.565^{* *}$ & $-0.447^{*}$ & $-0.512 *$ & $-0.708 * * *$ \\
\hline (interviewer) child upper extremities & -0.617 & -0.744 & -0.886 & -0.744 & $-0.974 *$ \\
\hline parent lower extremities & $-0.359 * * *$ & $-0.410 * * *$ & $-0.189 *$ & $-0.374 * * *$ & $-0.404 * * *$ \\
\hline parent upper extremities & $-0.487 * * *$ & $-0.284 *$ & -0.248 & $-0.402 * *$ & -0.236 \\
\hline
\end{tabular}

Note PEARSON CORRELATIONS (Spearman coefficients were also examined with similar results)

*Correlation is significant at the 0.05 level (2-tailed)

***Correlation is significant at the 0.01 level (2-tailed)

****Correlation is significant at the 0.00 I level (2-tailed)

a, Cannot be computed because at least one of the variables is constant

\section{Discussion}

Cerebral palsy with spasticity-related pain was a chronic and nonprogressive disease .As most of the normal population research, these children' quality of life become very complicated, due to various physiological and psychological factors. These may be the interacting factors from themselves, or the outside factors from the social environment and other people's thought. ${ }^{21,22}$ Comparing the PedsQL scores of CP with SRP to the general population in China showed that each domain and total scores was generally lower than that of normal children.

This result was similar to the previous research. ${ }^{10,23}$ But emphasizing all the CP population, these researches' inclusion standard was very different to our study which was focus on the $\mathrm{CP}$ with SRP. Beside the spastic type CP, they also included the other types such as athetosic type and the ataxia type CP. According to a cross-sectional survey in Europe, it was a growing recognition that pain was a significant problem for children and adolescents with $\mathrm{CP}$. More than $50 \%$ of children with CP suffered from pain from moderate to severe intensity everyday and at many parts of body. ${ }^{24,25}$ So, the spastic pain was a serious problem of $\mathrm{CP}$, and the children would always had the physical and psychological feeling of discomfort in the daily life because of the long-term existing of the pain. Ramstad $\mathrm{K}^{26}$ reported that recurrent muscle pain was associated with reduced accomplishment of daily activities $(\mathrm{B}=-1.22, \mathrm{p}=0.02)$ and social roles $(B=-1.17, p=0.03)$, and with reduced parental satisfaction with the accomplishment of daily activities $(\mathrm{B}=-1.14, \mathrm{p}=0.03)$ and social roles $(\mathrm{B}=-1.48, \mathrm{p}<0.01)$.

The main aim of the study was to analyze the correlation between the spastic pain in the cerebral palsy and their quality of life. As the discussion above, most CP quality of life was affected by spastic pain, but how the spastic pain affected the different aspects of the quality of the life? In the study, the child and parent proxy version QPS were used and correlation was found with each domain scores and total scores of the PedsQL. Most the LL/UL parent proxy-report QPS category reached the significance, compared to the LL/UL child QPS category. But the correlation between LL QPS and the PedsQL was more evident, according to the LL/UL child QPS category. This may be caused by excessive protect thought on their children in China. ${ }^{27}$ A study ${ }^{28}$ that assessed the relationship between parental distress and proxy-reported QOL for children with CP had a similar conclusion and that suggested that the parents' psychological state should also be measured when using parent proxy. It is particularly important if proxy-reported QOL was the only available data. A survey about the quality of life of children and their parents in Europe found similar problem. They found the mean child-reported scores of quality of life were significantly higher than the parent proxy reports. ${ }^{29}$ In our study, UL child QPS category total scores had a high correlation with each domain and the total scores of the PedsQL, but do not reach the significance. The result differed to most previous research. ${ }^{30,31}$ Reviewing the study, we found that the research of CP differ to the adult stroke and the lower limb problem was more serious and common than that of upper limb. Besides, patients with lower extremities accounted for most in this study, so the study was more representative for the lower limb CP. The lower limb spastic pain had moderate correlation with the physical, emotional, psychological, 
social function, and the result was similar to most research. ${ }^{6,23}$ But the correlation with the school function did not reach the significance which was caused by $\mathrm{CP}$ rehabilitation and education mode in China. Most time of the children was spend in the hospital, so the general school function was relatively poor.

As the discussion above, the correlation was moderate between the different situation and the total scores from the parent proxyreport PedsQL, and most of them reached the significance .Compared to the UL children report PedsQL, the LL had higher correlation with the these situations at activity / mobilization/dong hard activity and their significance reached 0.001 . But the correlation with the situation at rest was not evident which was inconsistent with previous research results. Most the research confirmed that the participation in leisure activities had a positive effect on the QOL of the children and adolescents with $\mathrm{CP}^{32}$ The conclusion was not always fit to the situation of CP children with SRP .Resting may had a positive effect on the $\mathrm{CP}$, but it is was very difficult for them to keep the posture of sitting and walking. On the contrary, when they try to finish the daily activity, they would felt the limitation from the spastic pain and these would lead to the negative influence to their mental health. ${ }^{33}$ This was also in agreement with previous studies with self-reports and proxyreports from parents showed that pain affected the emotional and psychological wellbeing in individual with $\mathrm{CP}^{34,35}$

$\mathrm{CP}$ is a chronic disease and its quality of life was a steady-state process. In this study, we found that, the results were very close and had no statistical significance between previous and post survey in the children or parents proxy-report PedsQL .So we should pay serious attention to the CP with SRP whether we had some good treatment to improve their quality of life or not. Assis $\mathrm{TR}^{36}$ had conducted a study to analyze quality of life (QOL) of children with CP treated with botulinum toxin type A. Sixty-eight patients were evaluated. The functional ability had improvement for all types of $\mathrm{CP}(\mathrm{p}=0.04)$.

This study has some limitations that must be taken into account for interpretation of results. The analysis of spastic pain and healthrelated quality of life in children and adolescents with cerebral palsy is base on the date from three sites in China, but the cases from the three sites is different, then it would reduce the representativeness of the general CP population with SRP.

\section{Acknowledgements}

None.

\section{Conflict of interest}

The authors declare no conflict of interest.

\section{References}

1. Rosenbaum P, Paneth N, Leviton A, et al. A report: the definition and classification of cerebral palsy April 2006. Dev Med Child Neurol Suppl. 2007;109:8-14.

2. Locatelli A, Incerti M, Paterlini G, et al. Antepartum and intrapartum risk factors for neonatal encephalopathy at term. Am J Perinatol. 2010;27(8):649-654

3. Basu A P, Clowry G. Improving outcomes in cerebral palsy with early intervention: new translational approaches. Front Neurol. 2015;6:24

4. Surveillance of cerebral palsy in Europe: a collaboration of cerebral palsy surveys and registers. Surveillance of Cerebral Palsy in Europe (SCPE). Dev Med Child Neurol. 2000;42(12):816-824.

5. Shi FR, Tang HX, Wang KL, et al. Sampling survey of risk factor pedo-cerebral palsy occurrence 95435 children. Chin J of clin rehabil. 2017;50(03):434-435.

6. Raina P, Donnell OM, Rosenbaum P, et al. The health and well-being of caregivers of children with cerebral palsy. Pediatrics. 2005;115(6):626636.

7. Van SW, Nieuwenhuijsen C, Van BE, et al. Participation and healthrelated quality of life in adults with spastic bilateral cerebral palsy and the role of self-efficacy. J Rehabil Med. 2010;42(6):528-535.

8. Badawi N, Kurinczuk JJ, Keogh J M, et al. Intrapartum risk factors for newborn encephalopathy: the Western Australian case-control study BMJ. 1998;317(7172):1554-1558.

9. Liu ZH, Lin QM, Wan RP, et al. Study on quality of life in children w ith cerebral palsy[J]. Chin J of clin. 2009;20(08):1327-133.

10. Huang XL, ZHang SH, Li JN, et al. Study on the quality of life of children with cerebral palsy and their family members. Chin J of child and woman health-care. 2012;56(21):3264-3266.

11. Mckearnan KA, Kieckhefer GM, Engel JM, et al. Pain in children with cerebral palsy: a review. J Neurosci Nurs. 2004;36(5): 252-259.

12. Kang HC. The problem of pain in patients with cerebral palsy: horizontal and vertical contrast confirmation study. Foreign Medical Sciences. 2005;60(04):183-184

13. Badia M, Riquelme I, Orgaz B, et al. Pain, motor function and healthrelated quality of life in children with cerebral palsy as reported by their physiotherapists. BMC Pediatr. 2014;14(05):192.

14. Gallien P, Nicolas B, Petrilli S, et al. Role for botulinum toxin in back pain treatment in adults with cerebral palsy: report of a case. Joint Bone Spine. 2004;71(1):76-78.

15. Lundy CT, Doherty GM, Fairhurst CB. Botulinum toxin type A injections can be an effective treatment for pain in children with hip spasms and cerebral palsy. Dev Med Child Neurol. 2009;51(9):705710.

16. Rivard PF, Nugent AC, Symons FJ. Parent-proxy ratings of pain before and after botulinum toxin type A treatment for children with spasticity and cerebral palsy. Clin J Pain. 2009;25(5):413-417.

17. Varni JW, Seid M, Kurtin PS. PedsQL 4.0: reliability and validity of the Pediatric Quality of Life Inventory version 4.0 generic core scales in healthy and patient populations. Med Care. 2001;39(8):800-812.

18. Varni JW, Seid M, Smith K T, et al. The PedsQL in pediatric rheumatology: reliability, validity, and responsiveness of the Pediatric Quality of Life Inventory Generic Core Scales and Rheumatology Module. Arthritis Rheum. 2002;46(3):714-725.

19. Yeung NC, Lau JT, Yu XN, et al. Psychometric properties of the Chinese version of the Pediatric Quality Of Life Inventory 4.0 Generic Core scales among pediatric cancer patients. Cancer Nurs. 2013;36(6):463473.

20. Geister TL, Quintanar SM, Martin M, et al. Qualitative development of the 'Questionnaire on Pain caused by Spasticity (QPS),' a pediatric patient-reported outcome for spasticity-related pain in cerebral palsy. Qual Life Res. 2014;23(3):887-896

21. Stuifbergen AK, Seraphine A, Roberts G. An explanatory model of health promotion and quality of life in chronic disabling conditions. Nurs Res. 2000;49(3):122-129. 
22. Batinica M, Grguric J, Jadrijevic CF. Chronic disease and health condition prevention in childhood-2nd part: emphases from the 14th Symposium of Preventive Pediatrics. Lijec Vjesn. 2014;136(1112):346-349.

23. Vles GF, Hendriksen RG, Hendriksen JG, et al. Quality of Life of Children with Cerebral Palsy: A cross-sectional KIDSCREEN study in the Southern part of the Netherlands. CNS Neurol Disord Drug Targets. 2015;14(1):102-9.

24. Parkinson KN, Gibson L, Dickinson HO, et al. Pain in children with cerebral palsy: a cross-sectional multicentre European study. Acta Paediatr. 2010;99(3):446-451.

25. Badia M, Riquelme I, Orgaz B, et al. Pain, motor function and healthrelated quality of life in children with cerebral palsy as reported by their physiotherapists. BMC Pediatr. 2014;14(09):192.

26. Ramstad K, Jahnsen R, Skjeldal O H, et al. Parent-reported participation in children with cerebral palsy: the contribution of recurrent musculoskeletal pain and child mental health problems. Dev Med Child Neurol. 2012;54(9):829-835.

27. Huo SY, Huang YL, Yang GE, et al. Establishing homelike nursing to the parents' excessive psychological reactions in hospital. Nursing study. 2004;10(24):2207-2208.

28. Davis E, Mackinnon A, Waters E. Parent proxy-reported quality of life for children with cerebral palsy: is it related to parental psychosocial distress?. Child Care Health Dev. 2012;38(4):553-560.
29. White KM, Arnaud C, Dickinson HO, et al. Determinants of childparent agreement in quality-of-life reports: a European study of children with cerebral palsy. Pediatrics. 2007;120(4):804-814.

30. Redman TA, Finn JC, Bremner AP, et al. Effect of upper limb botulinum toxin-A therapy on health-related quality of life in children with hemiplegic cerebral palsy. J Paediatr Child Health. 2008;44(78):409-414.

31. Sakzewski L, Carlon S, Shields N, et al. Impact of intensive upper limb rehabilitation on quality of life: a randomized trial in children with unilateral cerebral palsy. Dev Med Child Neurol. 2012;54(5):415-423.

32. Badia M, Longo E, Orgaz M B, et al. he influence of participation in leisure activities on quality of life in Spanish children and adolescents with Cerebral Palsy. Res Dev Disabil. 2013;34(9):2864-2871.

33. Shikako TK, Majnemer A, Law M, et al. Determinants of participation in leisure activities in children and youth with cerebral palsy: systematic review. Phys Occup Ther Pediatr. 2008;28(2):155-169.

34. White KM, Grandjean H, Colver A, et al. Parent and professional reports of the quality of life of children with cerebral palsy and associated intellectual impairment. Dev Med Child Neurol. 2008;50(8):618-624.

35. Kibele A. Occupational therapy's role in improving the quality of life for persons with cerebral palsy. Am J Occup Ther. 1989;43(6):371-377.

36. Assis TR, Forlin E, Bruck I, et al. Quality of life of children with cerebral palsy treated with botulinum toxin: are well-being measures appropriate?. Arq Neuropsiquiatr. 2008;66(3B):652-658. 